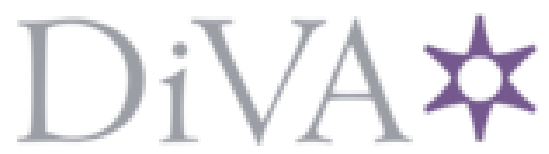

http://www.diva-portal.org

This is the published version of a paper published in Geotechnical and Geological Engineering.

Citation for the original published paper (version of record):

Spross, J., Johansson, F., Uotinen, L K., Rafi, J. (2016)

Using observational method to manage safety aspects of remedial grouting of concrete dam foundations.

Geotechnical and Geological Engineering, 34(5): 1613-1630

http://dx.doi.org/10.1007/s10706-016-0069-8

Access to the published version may require subscription.

N.B. When citing this work, cite the original published paper.

Permanent link to this version:

http://urn.kb.se/resolve?urn=urn:nbn:se:kth:diva-192817 


\section{Using Observational Method to Manage Safety Aspects of Remedial Grouting of Concrete Dam Foundations}

\section{Johan Spross, Fredrik Johansson, Lauri Kalle Tapio Uotinen \& Jalaleddin Yaghoobi Rafi}

\section{Geotechnical and Geological Engineering \\ An International Journal}

ISSN 0960-3182

Volume 34

Number 5

Geotech Geol Eng (2016) 34:1613-1630 DOI 10.1007/s10706-016-0069-8
ISSN 0960-3182

\section{Geotechnical and \\ Geological Engineering}

AN INTERNATIONAL JOURNAL

VOLUME 34 NUMBER 5 OCTOBER 2016

iㅡㄹ Springer

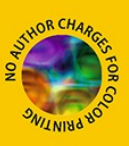

包 Springer 
Your article is published under the Creative Commons Attribution license which allows users to read, copy, distribute and make derivative works, as long as the author of the original work is cited. You may selfarchive this article on your own website, an institutional repository or funder's repository and make it publicly available immediately. 


\title{
Using Observational Method to Manage Safety Aspects of Remedial Grouting of Concrete Dam Foundations
}

\author{
Johan Spross 1 - Fredrik Johansson 1 - \\ Lauri Kalle Tapio Uotinen $(\mathbb{D} \cdot$ Jalaleddin Yaghoobi Rafi $\mathbb{B}$
}

Received: 17 February 2016/ Accepted: 8 August 2016/Published online: 17 August 2016

(C) The Author(s) 2016. This article is published with open access at Springerlink.com

\begin{abstract}
As concrete dams age, the need for remedial grouting to reduce the seepage and uplift pressure in the rock foundations under them increases. Based on a case study of a Swedish dam with very low calculated safety against sliding, this paper discusses the application of the observational method (as defined in Eurocode 7) to manage safety aspects during remedial grouting. The studied case was complex in that grouting works posed the risk of causing increased uplift pressure, which could have induced sliding failure along a shallow, persistent, horizontal rock
\end{abstract}

J. Spross $(\bowtie) \cdot$ F. Johansson · J. Y. Rafi

Department of Civil and Architectural Engineering, KTH

Royal Institute of Technology, 10044 Stockholm,

Sweden

e-mail: johan.spross@byv.kth.se

F. Johansson

e-mail: fredrik.johansson@byv.kth.se

J. Y. Rafi

e-mail: jrafi@bgcengineering.ca

\section{K. T. Uotinen}

Department of Civil and Environmental Engineering, Aalto University, PO Box 12100, Rakentajanaukio 4 A, 00076 Aalto, Finland

e-mail: lauri.uotinen@aalto.fi

Present Address:

J. Y. Rafi

BGC Engineering Inc., 980 Howe Street, Vancouver, BC V6Z 0C8, Canada joint in the foundation. The approach applied in the studied case mainly followed the principles of the observational method, except in some highly significant safety aspects for which alternative procedures are suggested and discussed. Implementing these procedures along with the observational method offers a coherent framework to manage the safety aspects of the remedial grouting of concrete dam foundations that is in line with modern risk-informed dam safety policies.

Keywords Observational method - Eurocode 7 . Dam safety $\cdot$ Foundation · Grouting

\section{Introduction}

An increasing number of dams worldwide are in need of repair and stability-enhancing modifications to satisfy safety regulations. For concrete dams founded on rock, an important safety measure to prevent dam failure by sliding or overturning is to reduce the uplift pressure in the foundation. The uplift pressure can be reduced by constructing a grout curtain or by providing drainage. Today, both methods are employed as a standard practice and are generally considered to complement each other (US Army Corps of Engineers 1984; International Commission on Large Dams 1993; Ruggeri 2004; Bernstone et al. 2009). 
The reducing effect of drains and grout curtains on the uplift pressure may not be permanent. With time, the grout curtain may deteriorate and the installed drains may become clogged (Ruggeri 2004; Fell et al. 2005), which can have a serious impact on dam safety (Spross et al. 2014a). The stability of dams against sliding and overturning can be improved by measures such as increasing the drainage capacity or re-grouting the foundation. The basic principles of curtain grouting design and construction are covered in US Army Corps of Engineers (1984), Houlsby (1990), Weaver and Bruce (2007), and Stille (2015).

Remedial grouting of an existing dam is more complex than grouting the foundation before a dam is built, mainly because water seepage through the rock foundation may displace the injected grout. Additionally, the applied grouting pressure may cause hydraulic jacking or increase the uplift pressure, both of which can affect dam stability. A remedial grouting operation has three fundamental stages: exploration and situation assessment, responsive execution, and verification and monitoring of performance (Bruce 2007). Examples of remedial rock grouting under concrete dams have been presented by Bruce et al. (1998), Bruce and Gillon (2003), Weaver and Bruce (2007), Bruce (2012), Wilson (2012), and Buckby et al. (2015).

These previous publications mainly cover the practical aspects of curtain grouting under dams and give recommendations for future projects. However, with the exception of the brief discussion of alarm levels for high uplift pressure in Buckby et al. (2015), they scarcely discuss the dam safety aspects that arise during the actual execution of remedial grouting. As many dam owners and dam safety authorities worldwide turn towards risk-informed dam safety activities (Australian National Committee on Large Dams 2003; Canadian Dam Association 2007a; Spanish National Committee on Large Dams 2012; Federal Energy Regulatory Commission 2014; US Army Corps of Engineers 2014; Federal Emergency Management Agency 2015), a practical guideline for how to plan remedial grouting under concrete dams could be of great use. For example, US Army Corps of Engineers (2014) states that "risks to a dam during the construction phase must be carefully identified, monitored and mitigated. This is especially true on items such as [...] grouting. A detailed plan must be required for any work related to these items."
This paper discusses the applicability of the observational method to manage dam safety aspects in remedial grouting projects for concrete dam foundations. This discussion is based on a case study of the remedial grouting of rock under a Swedish concrete dam, the procedure of which showed some striking similarities to the observational method. In short, the observational method offers a general framework that is particularly useful in geotechnical design when the structural behaviour is difficult to predict and associated with significant risks. The basic principle is to allow the design to be modified with predefined measures if observations of the ground behaviour indicate that the current design is unsuitable. Accordingly, the design should be adapted to the actual ground conditions. The aim of this paper is to expand the applicability of the observational method to remedial grouting projects of concrete dam foundations; identification of potential for wider use of the method was highlighted as a key issue in an ICE symposium (Powderham and Nicholson 1996). Therefore, the focus of the paper is how the requirements of the observational method can be satisfied. The case study is included to illustrate the procedure and does not attempt to present the state of the art in remedial grouting.

In this paper, the observational method is used in accordance with its definition in the current European code for the design of geotechnical structures: Eurocode 7 (European Committee for Standardization 2004). A first version of the method was defined by Peck (1969); two recent papers discussing that version are Wu (2011) and Serra and Miranda (2013). Regarding the Eurocode definition, few have discussed its application in detail, though Spross and Larsson (2014) and Christiansson et al. (2014) have studied its application to the grouting of rock tunnels; Zetterlund et al. (2011) have studied rock mass characterization for use in conjunction with the observational method in rock grouting; Stille and Holmberg $(2008,2010)$ and Spross et al. (2014b) have discussed some applications in rock engineering and the link to probabilistic design; and Prästings et al. (2014) have studied its application when constructing a high embankment on sulphide clay.

The remainder of this paper is organized as follows. In Chapter 2, the subject dam is described, and the background is given to why a grouting methodology with an observational approach was needed. In 
Chapters 3-5, the grouting methodology that was applied in the real case is compared step-by-step with the corresponding principles of the observational method as defined in Eurocode 7 (summarized in Fig. 1). For each principle, the similarities and differences between the applied methodology and the observational method are discussed with a focus on structural safety considerations. To overcome differences, improvements are suggested to the applied methodology. Lastly, the findings are summarized and a coherent framework is presented to manage risks in the remedial grouting of concrete dam foundations.

\section{Case Background}

\subsection{Dam Description and Initial Conditions}

Remedial grouting has been conducted in the rock under the concrete spillways of a Swedish hydropower dam (not identified at the owner's request). The spillway section is of a buttress type and consists of three hollow spillway chutes between four piers. The spillway section is divided into four monoliths (Fig. 2). The underlying rock consists of fine-grained and coarse-grained granite with some pegmatite intrusions. Rock anchors were installed when the dam was built in the 1960s (their dimensions and quality are unknown, owing to lost drawings). In a safety reassessment made in 2006, the computed safety factor against sliding was found to be unacceptable, despite the good rock mass quality (Geological Strength Index $=60-80$ ), because of the detection of a shallow and persistent horizontal

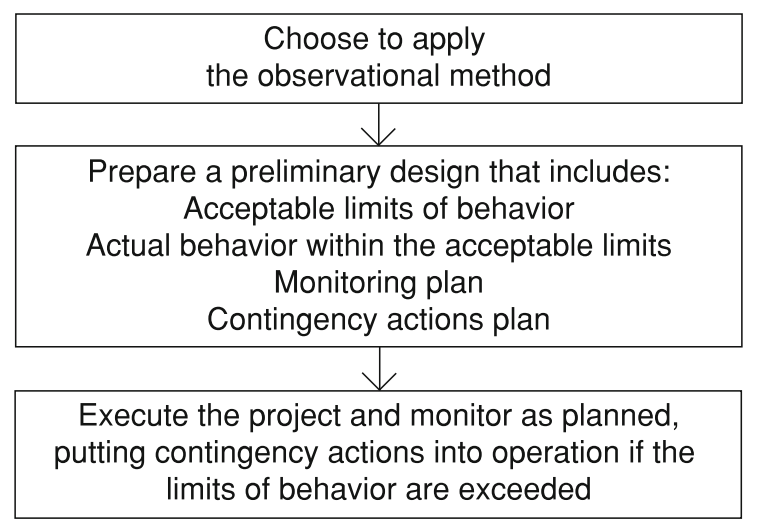

Fig. 1 Overview of the observational method as defined in Eurocode 7. Each principle is discussed and compared to the case

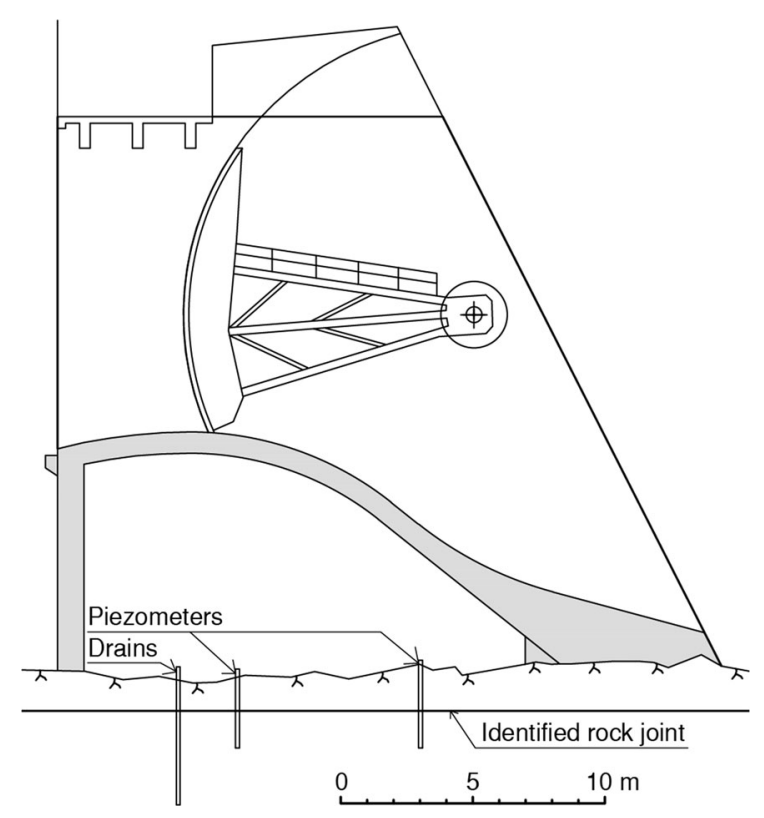

Fig. 2 Cross section of a spillway monolith seen from the side. A shallow and persistent horizontal rock joint led to low sliding stability

rock joint extending under three of the monoliths (Figs. 2, 3, 4).

To improve the sliding stability, drilled and grouted micropiles were planned for installation. However, first, to avoid the immediate erosion of the grout when installing the micropiles, remedial grouting of the curtain was required to reduce the flow rates. This would, in itself, also increase the sliding stability by decreasing the uplift pressure. The stability-enhancing modifications started in October 2011.

\subsection{A Dramatic Event Complicating the Project}

On 15 November 2011, a dramatic event caused serious problems. While drilling hole 1 and 2 in the first row of boreholes for the remedial grouting (to the left of and under pier 2 in Fig. 5), the infill of a fracture, $\sim 200 \mathrm{~kg}$ of sand, was unexpectedly washed out from these holes. Later, while drilling hole 5 in the same row, the flow rate emerging from the new boreholes increased from 0.5 to $4.7 \mathrm{~L} / \mathrm{s}$. This event was registered an immediate drop in uplift pressure at piezometer $\mathrm{P} 2$, as the leakage improved the drainage capacity (Fig. 6). The flow was large enough to completely flood a temporarily installed weir. The fracture aperture was estimated to be $1-10 \mathrm{~cm}$ 


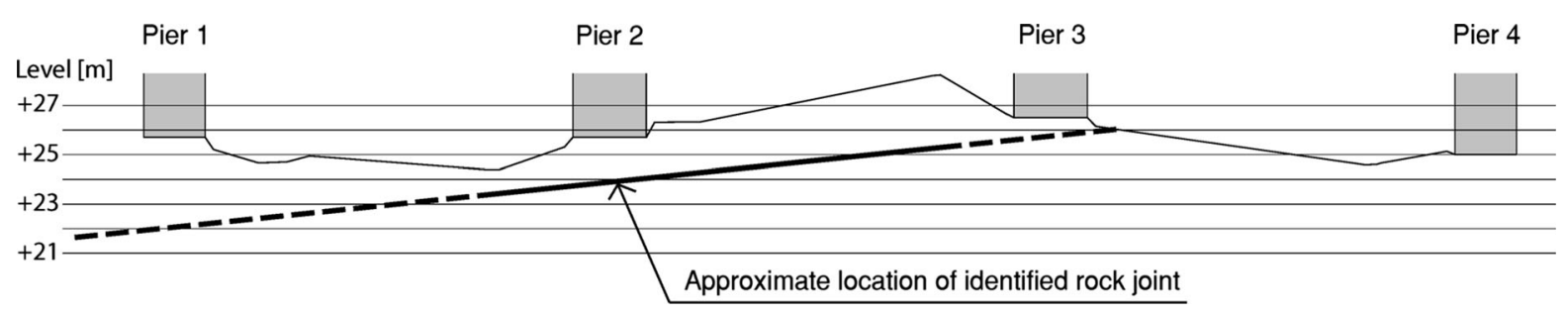

Fig. 3 Cross section of the spillway section seen from the upstream face of the dam
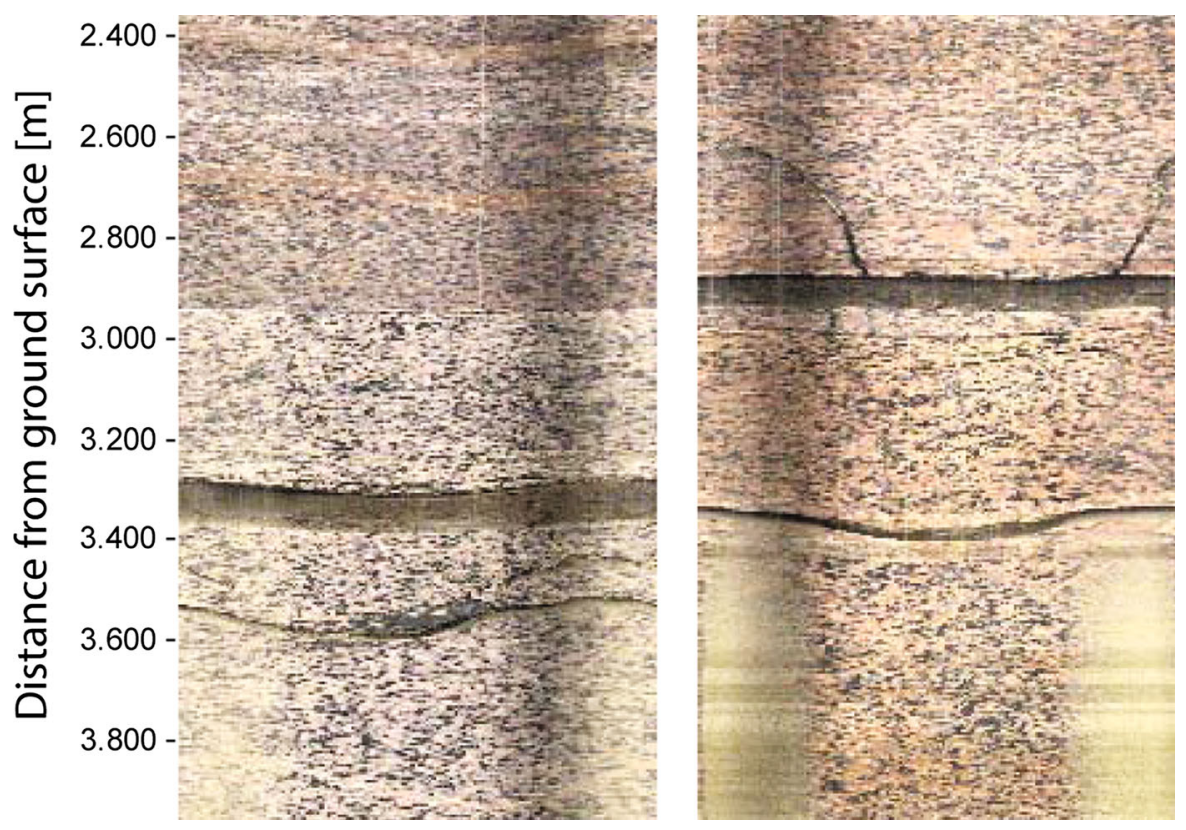

Fig. 4 Images of the persistent fracture taken in two boreholes (diameter: $76 \mathrm{~mm}$ ) close to pier 2 with a borehole camera in December 2008. The fracture was found to be partially filled with grout. (The ground surface level differs slightly between the two boreholes)

(Fig. 4). Although the uplift pressure dropped, which increased the safety margin against the sliding of the dam, the planned grouting had to be redesigned and extended to seal this new leakage as well, as the grouted micropiles were yet to be installed.

Despite several attempts with heat cement grout, the seepage could not be sufficiently reduced (although the total flow rate did decrease from 4.7 to $1.5 \mathrm{~L} / \mathrm{s})$. After grouting a second row of boreholes (holes 7-11 in Fig. 5) along the curtain, the grouting was considered completed except for the large local leakage under pier 2. After additional sealing attempts, including the drilling and grouting of three more boreholes (G1-G3), the designer judged that the current grouting methodology was inadequate. Therefore, a new and improved grouting methodology had to be developed.

\subsection{Improved Grouting Methodology for Local Leakage Under Pier 2}

The main improvement made in the new methodology was the drilling of two relief wells (RW12 and RW34 in Fig. 5) to reduce the uplift pressure and seepage flow. This would enable the grouting of a horseshoe-shaped curtain (boreholes 31, 32, 37, 38, and 51-58 in Figs. 5, 7) beside and downstream of the relief wells to enclose the leaking area. Thereafter, the two relief wells (RW12 and RW34) could be sealed. The enclosed area could then be grouted, as the new horseshoeshaped curtain would serve as a barrier for the flow.

In the worst case, three possible consequences of the grouting works that could induce sliding of the dam were identified during the design process: excessive hydraulic jacking due to an overly high grout 


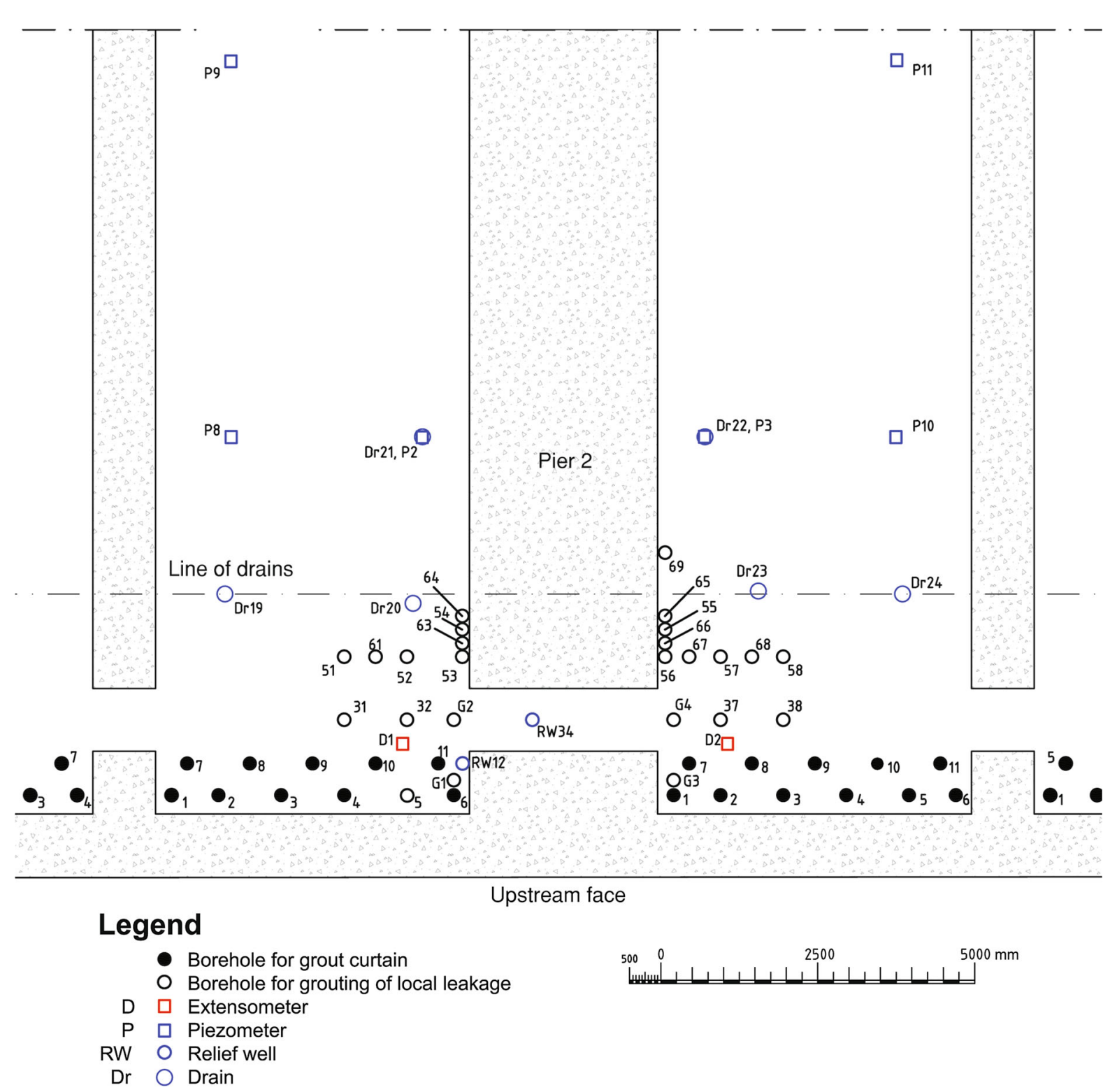

Fig. 5 Plan view of the boreholes used to seal the leakage under pier 2 (by RW34). Two relief wells and a surrounding horseshoe-shaped grout curtain (unfilled black circles) were pressure, increasing piezometric water pressure in the foundation, and washout of infill material. Thus, these aspects had to be monitored throughout the project. A monitoring program was supplemented with contingency action plans to be put into operation if the predefined limits of acceptable behaviour for the monitored parameters were exceeded. In the following, the applied grouting methodology and its possible effects on dam safety in light of the definition of the observational method in Eurocode 7 are discussed. required to reduce the flow so that the area enclosed by the curtain could be grouted to seal the leakage

\section{Observational Method and the Real Case in Comparison}

The observational method in Eurocode 7 (Fig. 1) is defined by five paragraphs, which are quoted in full in the following sections. The first introduces the method and suggests when it is suitable for application:

"When prediction of geotechnical behaviour is difficult, it can be appropriate to apply the 


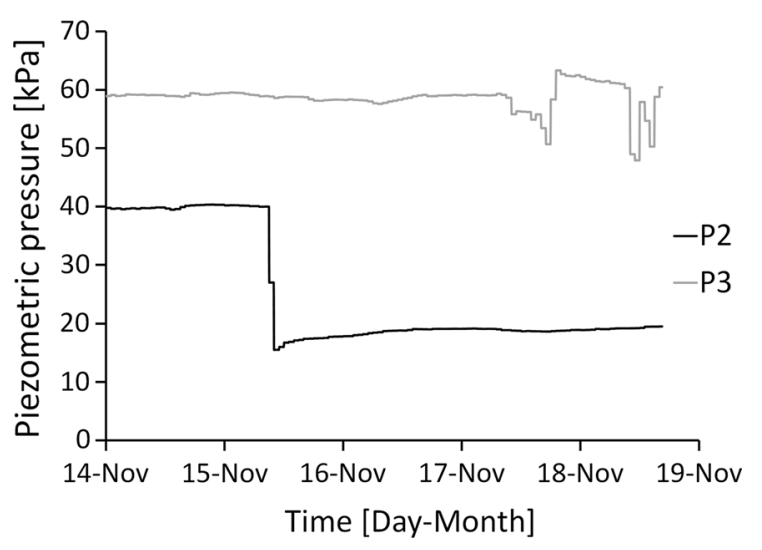

Fig. 6 Measured piezometric water pressure in piezometers P2 and P3 (locations shown in Fig. 5) around the time of the washout on November 15, 2011

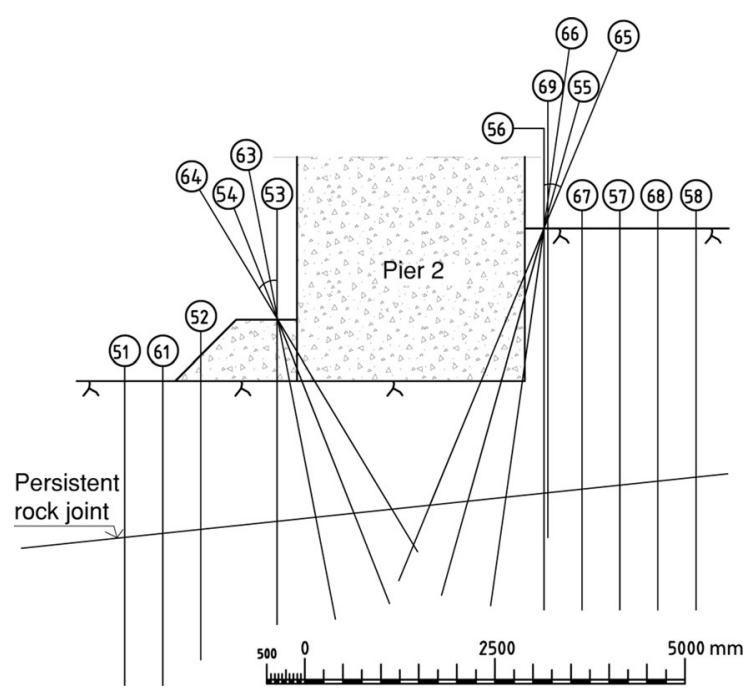

Fig. 7 Cross section along the line of drains in Fig. 5. Inclined boreholes were used under the pier to seal the horseshoe-shaped grout curtain

approach known as 'the observational method', in which the design is reviewed during construction." (European Committee for Standardization 2004)

Below, the authors examine whether such conditions were present in the studied case and highlight those features that are of relevance in choosing the observational method.

\subsection{Hydraulic Jacking: The Main Reason to Apply the Observational Method}

Injecting grout of suitable pressure is of particular importance when grouting in rock close to the ground surface. Too low pressures may mean that the grout does not spread to the required distance; too high pressures may cause increased seepage and uplift pressure under the dam by causing undesired permanent deformations in the rock mass (hydraulic jacking) or washing out infill material from the joints. Thus, using an overly high pressure could initiate sliding failure of the dam.

In principle, jacking behaviour can be interpreted as disengagement of the asperities that are in contact with each other caused by the joint being subjected to the grout pressure. Once the grout pressure exceeds the initial normal stress on the joint, the joint dilates elastically until ultimate hydraulic jacking occurs when the bearing capacity is exceeded (Gothäll and Stille 2009).

As a rough guide, US Army Corps of Engineers (1984) suggests a maximum allowable grout pressure, $p_{g, \text { max }}$, of $0.011 \mathrm{MPa} / \mathrm{m}$ of rock cover to avoid hydraulic jacking; however, it also mentions that higher pressures can be safely used in many cases.

From a theoretical basis, Brantberger et al. (2000) proposed an equation for $p_{g, \max }$ and Stille et al. (2012) modified this equation by including groundwater pressure as follows:

$\frac{\Delta p_{g} k_{2}}{3 \rho g h}+\frac{p_{w}}{\rho g h} \leq 1+\frac{1}{I_{n}}+\frac{1}{3 I_{n}^{2}}$

where the relative grout spread, $I_{n}$, is defined as

$I_{n}=\frac{I}{h}$

and $p_{g, \text { max }}$ is given by

$p_{g, \max }=\Delta p_{g}+p_{w}$

In Eq. (1), $p_{w}$ is the piezometric water pressure; $\rho$ is the rock mass density; $g$ is the acceleration due to gravity; $h$ is the depth to the joint measured from the ground surface; $\Delta p_{g}$ is the effective grout pressure (that exceeds $p_{w}$ ); $k_{2}$ is a parameter describing the relative area of contact in the joint; and $I$ is the grout spread. In the case of infinite grout spread, Eq. (1) implies that the loading from the effective grout pressure and piezometric water pressure may not exceed the weight of the overburden, if hydraulic 
jacking is to be avoided. See Rafi (2014) for a more detailed discussion of Eq. (1).

The complexity of the studied case was mainly attributable to the possibility of inducing hydraulic jacking in the identified persistent horizontal rock joint, along which sliding failure of the dam was feared. At the grouted area, the joint was subject to an insignificant, possibly non-existent, normal stress owing to its position at the dam heel. Furthermore, the reservoir head implied an already high $p_{w}$ in the foundation, which had to be exceeded by the grout pressure (Eq. 1). Notably, as the rock cover above the joint was only $3 \mathrm{~m}$, the US Army Corps of Engineers (1984) would suggest a $p_{g, \max }$ significantly less than the expected $p_{w}$.

Although the rigid dam body and old rock anchors contributed a stabilizing effect, the risk of sliding failure caused by the effects of hydraulic jacking could not be disregarded. In addition, the significant idealizations in Eq. (1) meant that whether the equation was applicable in this complex case was questionable.

\subsection{Additional Reasons to Apply the Observational Method}

In addition to the estimation of the allowable $p_{g, \max }$, the studied case included other difficulties and risks. Accidental clogging of the drains by grout could also increase the uplift pressure and thereby affect the sliding stability. Another risk, which is independent, however, of the applied grouting procedure, was the possibility of infill material washing out from the fracture when drilling boreholes. If the washout were significant, it could induce local subsidence of the rock mass, causing increased leakage and reduced shear capacity against sliding failure.

The detected risks associated with remedial grouting were found to be easier to manage by carefully observing the behaviour of the foundation. Therefore, given the site conditions and the complex response of the rock mass when grouting, the geotechnical behaviour was considered difficult to predict, making the observational method a viable option.

\section{Preparations During the Design Stage}

To apply the observational method properly, there are five requirements listed in Eurocode 7 that must be fulfilled in the preliminary design (Fig. 1). This rules out the common misinterpretation of the observational method as a design-as-you-go approach (Schubert 2008). Instead, a framework of predefined contingency actions to put into operation is set up a priori, in case the geotechnical behaviour turns out to be unacceptable. Sections 4.1-4.4 of this paper quote and discuss one of these requirements at a time in relation to the remedial grouting design that was prepared in the real case.

\subsection{Acceptable Limits of Behaviour}

Eurocode 7 (European Committee for Standardization 2004) states the following:

"The following requirements shall be met before construction is started:

- acceptable limits of behaviour shall be established."

To reasonably document that dam safety was acceptable throughout the project, three control parameters were chosen for remedial grouting: uplift pressure, vertical displacement, and visual detection of infill material being washed out of boreholes. The choice of control parameters is an important aspect of the observational method. According to Spross (2014), suitable control parameters should

- make it possible to establish a limit of behaviour that is linked to a predicted behaviour of the structure,

- be measurable with acceptable precision, and

- be of epistemic nature (as discussed by Stille and Holmberg 2010), which implies that the related uncertainty is because of a lack of knowledge rather than because of intrinsic randomness of a phenomenon (see e.g. Der Kiureghian and Ditlevsen 2009; Baecher 2016). Having epistemic uncertainties, the measurements in the construction stage will decrease the uncertainties of the assumptions made in the design stage.

The chosen control parameters satisfied these criteria: they were related to the sliding failure of the dam, were believed to be measurable (or observable) precisely enough to support any decision to use contingency actions, and the measurements would decrease the uncertainties of the prior assumptions. An 
example of a prior assumption is the commonly assumed bilinear uplift pressure distribution, used in, for example, Swedenergy (2012) and Federal Energy Regulatory Commission (2002), which are Swedish and American guidelines for dam safety, respectively. The choices of the control parameters were straightforward because they could be monitored using fairly simple instruments.

Limits of acceptable behaviour (alarm thresholds) that were linked to the control parameters were established. The maximum average piezometric water pressure allowable in the rock joint downstream of the drains, $\bar{u}_{\text {joint } \text {,lim }}$, was set to $56 \mathrm{kPa}$ (Fig. 8). This limit corresponded directly to an average piezometer reading, $\bar{u}_{\text {piez,lim }}$, of $70 \mathrm{kPa}$ (the piezometers were positioned below the rock joint).

For hydraulic jacking, a maximum allowable uplift displacement, $\delta_{\text {lim }}$, of $0.2 \mathrm{~mm}$ was established in accordance to the rule of thumb long used by the Swedish State Power Board (Statens Vattenfallsverk 1968). The limit for observed infilling material was set to "visible washout." The established limits were based on the maximum values that, at the time, were

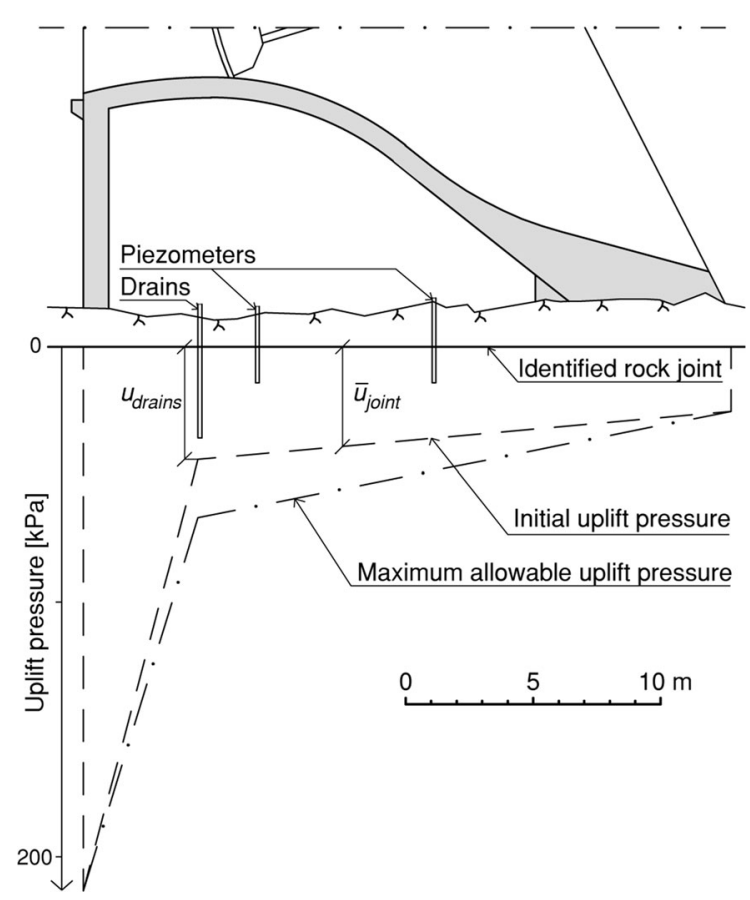

Fig. 8 Cross section of spillway monolith 2 showing the initially measured average uplift pressure, $\bar{u}_{\text {joint }}$, downstream of the drains in comparison to the maximum allowable uplift pressure, $\bar{u}_{\text {joint,lim }}$. The joint orientation is clear from Fig. 3 believed to maintain an adequate factor of safety. In the following, the defined limits are discussed with respect to their impact on dam safety.

\subsubsection{Discussion of the Acceptable Limit for Average Uplift Pressure}

In this case, the uplift pressure had a significant influence on the calculated safety factor against sliding failure. In Table 1, safety factors are shown for various assumed $\bar{u}_{\text {joint }}$ values in the range of previously measured pressures (Fig. 6). The safety factors were calculated assuming an uplift pressure distribution shaped as in Fig. 8 and, for the rest, in accordance to the Swedish dam safety guidelines (Swedenergy 2012). The stability assessment conservatively excluded the resistance provided by the old rock anchors owing to their unknown condition. Table 1 shows that both the initial conditions and the $\bar{u}_{\text {joint }, \text { lim }}$ value corresponded to very small calculated safety factors that were significantly less than 1.35 , which is the safety factor recommended by Swedenergy (2012) for a usual load case. In fact, even a moderate uplift pressure increase could have reduced the safety factor below 1. Therefore, the following presents an improved approach that keeps the risk for sliding failure at an acceptable level in case of a sudden increase in piezometric water pressure while executing grouting.

In the general case, an increased $\bar{u}_{j o i n t}$ value can be directly linked to a change in the calculated probability of failure. For example, a dam owner can choose to accept the risk associated with subjecting the dam to an additional uplift pressure so that the probability of sliding failure increases by $\Delta p_{f, a c c}$. In deterministic terms, this may correspond to decreasing the safety factor from the initial $S F_{\text {init }}$ to the smallest acceptable safety factor, $S F_{a c c}$ (Fig. 9a). For infrequent (exceptional) load cases, such as temporary loads

Table 1 The effect of $\bar{u}_{\text {joint }}$ on the calculated safety factor against sliding failure

\begin{tabular}{ll}
\hline Assumed $\bar{u}_{\text {joint }}(\mathrm{kPa})$ & Safety factor \\
\hline 40 & 1.09 \\
50 & 1.06 \\
60 & 1.03 \\
70 & 1.00 \\
\hline
\end{tabular}


during construction work, the Swedish guidelines (Swedenergy 2012) require $S F_{\text {exc }}=1.1$. For reference, the Canadian Dam Association (2007b) and the US Federal Energy Regulatory Commission (2002) require $S F_{\text {exc }}=1.3$ for similar load cases. Executing remedial grouting implies loads that are arguably transient; designing for safety factors of exceptional load cases can therefore be acceptable for actual grouting works. However, if the elapsed time from discovering a need for stability improvement to completing the stability enhancement is significant, the dam owner may need to meet the requirement for usual load cases, e.g., $S F_{\text {usual }}>1.5$ (Federal Energy Regulatory Commission 2002), because the loads are no longer transient.

As the safety factor may not decrease below $S F_{a c c}$, executing remedial grouting under a dam with $S F_{\text {init }}>S F_{\text {acc }}$ is acceptable only if the additional loads from grouting are small enough to continuously keep $S F>S F_{a c c}$. The limit of acceptable behaviour
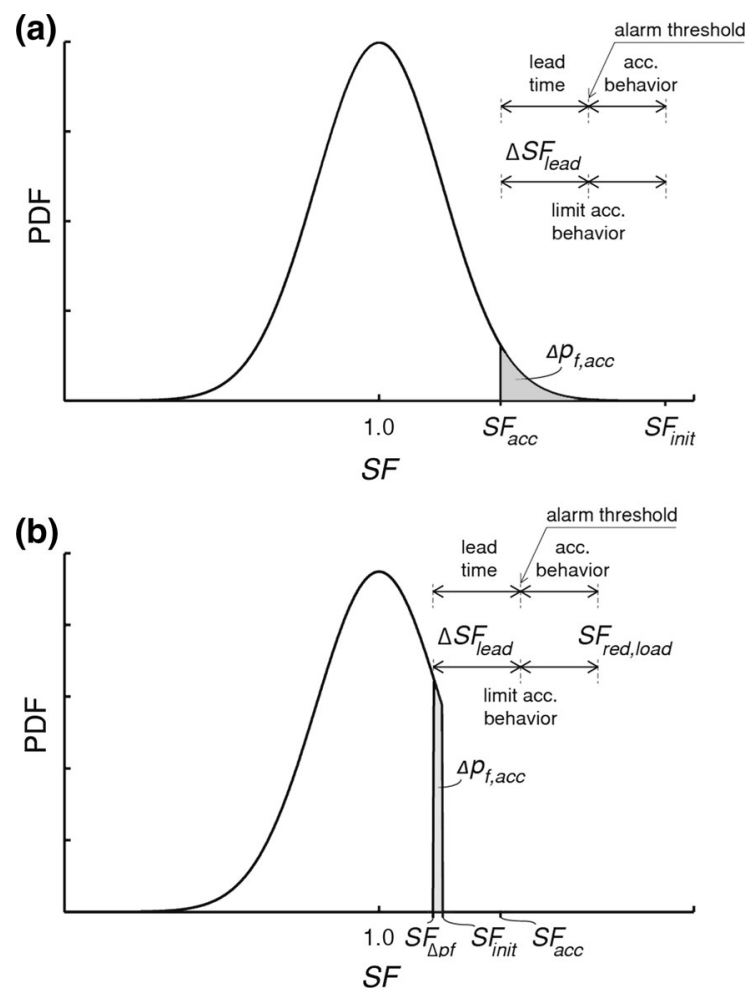

Fig. 9 Probability distribution indicating the structural reliability in relation to calculated $S F$ (assuming that $50 \%$ of all dams would fail if their $S F$ s were decreased to 1). The required lead time and limit of acceptable behavior in relation to $S F_{\text {init }}$ are indicated. In $\mathbf{a} S F_{\text {init }}>S F_{a c c}$, and in $\mathbf{b} S F_{\text {init }}<S F_{a c c}$ must, therefore, be established such that the lead time allows for contingency actions to be put into operation before $S F_{a c c}$ is reached (Fig. 9a) (Paté-Cornell and Benito-Claudio 1987, Olsson and Stille 2002).

For some dams, like the studied dam with $S F_{\text {init }}=1.06$, the relationship $S F_{\text {init }}<S F_{\text {acc }}$ may hold. A dam owner willing to accept the same increase in failure probability, $\Delta p_{f, a c c}$, during the grouting works, regardless of the initial safety calculation, consequently accepts additional loads until $S F_{\Delta p f}$ is reached (Fig. 9b). However, the margin between $S F_{\text {init }}$ and $S F_{\Delta p f}$ may not always provide the required safety margin to allow for the lead time and a range of acceptable behaviour. An additional margin can then be created by reducing the driving loads on the dam, until a safety factor $S F_{\text {red,load }}$ is reached. Some options are to perform grouting during the summer to avoid ice loads, to install rock anchors, or to lower the reservoir level temporarily. However, as discussed above, the dam must not be subjected to a very low value of $S F$ for long periods. Therefore, waiting for several months before conducting grouting works, for example, to avoid ice loads, becomes questionable.

Even if $S F<S F_{a c c}$ during project execution, the suggested approach conforms to Federal Energy Regulatory Commission (2002), which notes that the required safety factor should reflect the degree of uncertainty in the safety assessment. This is visualized by the truncated probability distribution in Fig. 9b; the dam is stable for $S F>S F_{\text {init }}$, and it can only fail if it is subjected to loads larger than any previously experienced load. Therefore, the limits of acceptable behaviour may correspond to a safety factor less than $S F_{a c c}$.

In practice, the assessment of $\Delta p_{f, a c c}$ and $S F_{\Delta p f}$ can be troublesome for dams with very low $S F_{\text {init }}$. However, considering the significant probability density causing failure adjacent to the $S F_{\text {init }}$ in Fig. $9 \mathrm{~b}$, $\Delta p_{f, a c c}$ implies only a limited acceptable decrease from $S F_{\text {init }}$. Consequently, $S F_{\Delta p f}$ may, for practical convenience and for a conservative solution, be approximated with $S F_{\text {init }}$.

To illustrate this concept, a limit of acceptable behaviour and the corresponding lead time is presented for the studied dam. Given the fact that $S F_{\text {init }}=1.06$ is already low, no additional decrease in safety is allowable in practice. The current loads must, therefore, be decreased to create a safety margin until a 
satisfactory $S F_{\text {red,load }}$ is reached. The required lead time for the contingency action (increasing the drainage capacity in case it is insufficient) is estimated to be $15 \mathrm{~min}$, given that the drill rig is on standby. The rate of increase of the piezometric pressure is assumed to be $100 \mathrm{kPa} / \mathrm{h}$ at the piezometers, until arriving at the linear pressure distribution normally assumed for dams without drains. For the same range of acceptable uplift pressure as before (less than the limit of acceptable behaviour $\bar{u}_{\text {joint,lim }}$ ), the average maximum uplift pressure in the joint as measured by the piezometers becomes $\bar{u}_{\text {joint,lim }}+25 \mathrm{kPa}$. This corresponds to a piezometric pressure at the drains, $u_{\text {drains }}$, of $90 \mathrm{kPa}$ (Fig. 8). To keep the risk level constant, this requires a drawdown of the reservoir level by at least $1.5 \mathrm{~m}$ (Table 2). Assuming that the drawdown does not affect the initial uplift pressure (Fig. 6), $S F_{\text {red,load }}$ would be 1.21 when the grouting work begins. If $\bar{u}_{\text {joint }, \text { lim }}$ is reached, $S F=1.15$ for a reduced reservoir level.

Unfortunately, this safety margin was not clearly analysed and established in the actual execution of the grouting works. Notably, an increase in piezometric pressure at the drains to $90 \mathrm{kPa}$ without decreasing any other load would have implied $S F$ of 0.93 , excluding the resistance provided by the old rock anchors.

\subsubsection{Discussion of the Maximum Acceptable Deformation}

For hydraulic jacking, the major issue was not the vertical displacement in itself but, rather, the possible consequences of a widened fracture: a significantly increased flow rate and subsequently, increased uplift pressure. Thus, a case of elastic jacking, which retracts once the grouting pressure subsides, was, at the time, considered unproblematic for the structural safety of the dam. The major risk was considered to be the consequences of ultimate (irreversible) jacking. However, a dilation of the grouted fracture may open up or close nearby fractures (Fransson et al. 2010). In Rafi and Stille (2015a), it was shown theoretically that this significantly could increase the transmissivity of the rock joint immediately outside the grouted area; in Rafi and Stille (2015b), this aspect was discussed in the light of three case studies. When a high-quality grout curtain with minimum leakage is desired, hydraulic jacking should be avoided completely. Consequently, a precision issue is introduced; such small deformations may be very difficult to detect as other rock joints nearby might, at least partially, absorb the deformation. Recently, Lin et al. (2016) presented a case study of a foundation grouting under an arch dam, where uplift deformation measurements with a $10-\mu \mathrm{m}$ precision were used to adjust the pressure and injection rate of the grout.

In retrospect, the choice of measurement equipment for monitoring hydraulic jacking is highlighted as a crucial aspect. Another method to detect hydraulic jacking that could be used as a complement is to continuously monitor, for example, flows, pressures, and apparent Lugeon values; owing to the increased use of computer monitoring in the grouting industry in the past decade, such approaches have improved rapidly (Wilson 2012; Bruce 2012). Wilson (2012) gives examples of application of apparent Lugeon theory; two other grouting approaches based on monitoring are the Aperture Control Grouting approach (Bonin et al. 2012; Carter et al. 2012) and the Real Time Grouting Control method (Rafi and Stille 2014).

Striving to avoid hydraulic jacking sets high demands on grouting. Low grout pressure is required; nonetheless, the piezometric water pressure at the point where grout is being injected must be overcome

Table 2 Effects of increased uplift pressure and reduced reservoir level on $S F$ of the studied dam

\begin{tabular}{lllll}
\hline Load case & $\begin{array}{l}\text { Piezometric } \\
\text { pressure }(\mathrm{kPa})\end{array}$ & $\begin{array}{l}S F \text { without } \\
\text { drawdown }^{\mathrm{a}}\end{array}$ & $\begin{array}{l}\text { Required drawdown }(\mathrm{m}) \\
\text { for constant risk level }\end{array}$ & $\begin{array}{l}S F \text { after } \\
\mathrm{drawdown}^{\mathrm{a}}\end{array}$ \\
\hline Constant uplift pressure & 50 & 1.06 & 0 & 1.06 \\
Large uplift pressure increase & 90 & 0.93 & -1.5 & 1.21 \\
\hline
\end{tabular}

${ }^{a}$ Swedenergy (2012) was used to assess the loads in calculating the safety factors 
to enable grouting to be performed. The compromise of these two aspects gives the best possible solution given the circumstances: grout pressure that barely exceeds the piezometric water pressure to minimize $\Delta p_{g}$ and the probability of causing hydraulic jacking. Doing so reduces the risk of inducing significantly increased uplift pressure.

\subsection{Design for Actual Behaviour Within the Acceptable Limits}

The second Eurocode requirement states that the designer must show that the preliminary design has an acceptable probability of enabling successful construction, thus limiting the need for contingency actions (European Committee for Standardization 2004):

- "the range of possible behaviour shall be assessed and it shall be shown that there is an acceptable probability that the actual behaviour will be within the acceptable limits."

For uplift pressure, the range of possible behaviour was assessed to be within full headwater and full tailwater pressure, because of the unknown subsurface drainage conditions. The margin to $\bar{u}_{\text {joint } \text {,lim }}=56 \mathrm{kPa}$ (i.e., $\bar{u}_{\text {piez,lim }}=70 \mathrm{kPa}$ ) was judged to be large enough to assume that exceeding the piezometric pressure limit was sufficiently unlikely, as the piezometers indicated pressures in the range of $30-50 \mathrm{kPa}$ before grouting started.

By setting $\delta_{\text {lim }}$ to a displacement $(0.2 \mathrm{~mm})$ that was judged small, the range of elastic displacement was believed to provide a safety margin against ultimate hydraulic jacking (although it was noted that this margin was very difficult to quantify). Notably, as grouting could easily be stopped the moment any displacement was recorded, to let the displacement retract, a rather high probability could be accepted for exceeding $\delta_{\text {lim }}$.

The possibility of causing yet another washout of infill material was considered significant, as this had already happened once. Although a subsequent flow rate increase would imply even more difficulties in grouting being completed successfully, the event is not dangerous unless the drainage capacity is exceeded.
Notably, the probabilities of exceeding the acceptable limits were not calculated numerically; instead, they were assessed subjectively to be sufficiently unlikely. Whether this approach is acceptable is discussed in the following.

\subsubsection{Discussion of the Subjective Probability Judgments}

Had the observational method been applied formally, not establishing the probability of exceeding the acceptable limits is a deviation from the Eurocode principles. However, Spross and Larsson (2014) argue that this deviation should occasionally be acceptable, because the effect on the project is only that the need for contingency actions remains unknown (assuming that the project can manage a significant increase in contingency actions). Thus, if the contingency actions must be implemented more often than expected, this could delay the project significantly and increase the total cost. Not fulfilling this Eurocode principle makes it difficult to find a more favourable design, thereby losing some optimization potential. However, the safety of the structure is not threatened as long as the contingency actions may be put into operation more frequently than originally planned.

In the studied case, it would have been very difficult to objectively assess the probabilities of exceeding the acceptable limits owing to the nature of the problem. In addition, given the relatively economic and simple contingency actions that were prepared for the case of an exceeded limit (see Sect. 4.4), it is rather unreasonable to say that the inability to fulfil this particular Eurocode requirement should stop the project. To some degree, the cost was subordinate to the importance of improving the safety of the dam. This situation is different from a case in which the observational method is only one of several options and a more favourable method is to be chosen. A numerical assessment of the probabilities of exceeding the limits would then provide crucial information about possible cost increases and time delays. However, when comparing the Eurocode version of the observational method with Peck's definition, it becomes evident that such a strict interpretation was never the originator's intention: "The degree to which all these steps can be followed depends on the nature and complexity of the work" (Peck 1969). For example, this interpretation could imply assessing 
the probability of exceeding the acceptable limits only subjectively, in a manner similar to the studied case.

For a practical solution, the authors argue that if the execution of the project depends on whether this Eurocode requirement can be fulfilled, a less strict interpretation should be acceptable. However, in such cases, the design engineer must be aware that a less rigorous analysis implies larger uncertainties regarding the final cost.

\subsection{On the Monitoring Plan}

The third and fourth requirements state the following (European Committee for Standardization 2004):

- "a plan of monitoring shall be devised, which will reveal whether the actual behaviour lies within the acceptable limits. The monitoring shall make this clear at a sufficiently early stage, and with sufficiently short intervals to allow contingency actions to be undertaken successfully."

- "the response time of the instruments and the procedures for analysing the results shall be sufficiently rapid in relation to the possible evolution of the system."

The grouting instructions in the studied case included a monitoring plan. The piezometric water pressure was to be monitored using six piezometers (Fig. 5). They were to be continuously checked in an automatic system both during grouting and until at least $4 \mathrm{~h}$ after grouting was finished or until the piezometric pressures had stabilized. The vertical displacement was to be continuously monitored during grouting at two places using extensometers (Figs. 5, 10). The staff at the site was to be observant of any signs of a washout occurring.

If the behaviour were found unacceptable during or after the grouting, contingency actions (see below) were prepared to immediately be put into operation. The continuous reading of the instruments and the very straightforward analysis of the measurement data were believed to make the time between exceeding the limit and taking action acceptably short. In addition, as $\bar{u}_{\text {piez,lim }}$ was defined as the average given by the four piezometers penetrating the persistent fracture, exceeding this limit in only one piezometer allowed for contingency measures to reduce the pressure before it had spread too far. However, a case of sudden uplift pressure increase under the whole monolith would have been very difficult to handle. Such a situation was, on the other hand, considered very unlikely as this would require the leakage to increase so much that it exceeded the total drainage capacity.

One objective of a monitoring plan is to gather information that establishes whether the current design is sufficient or needs to be changed. In this case, fairly simple devices and methods were used and little data analysis was needed; this limited the likelihood of both misinterpreting the results and communication delays. In that sense, the two Eurocode requirements were fulfilled. However, this conclusion presumes that the sensors covered the relevant area, were correctly installed, and fully functional during the work. For example, Hanna et al. (1993) reported that uplift pressures for a given dam can be highly variable, depending on local irregularities in the foundation. Moreover, Nicholson et al. (1999)

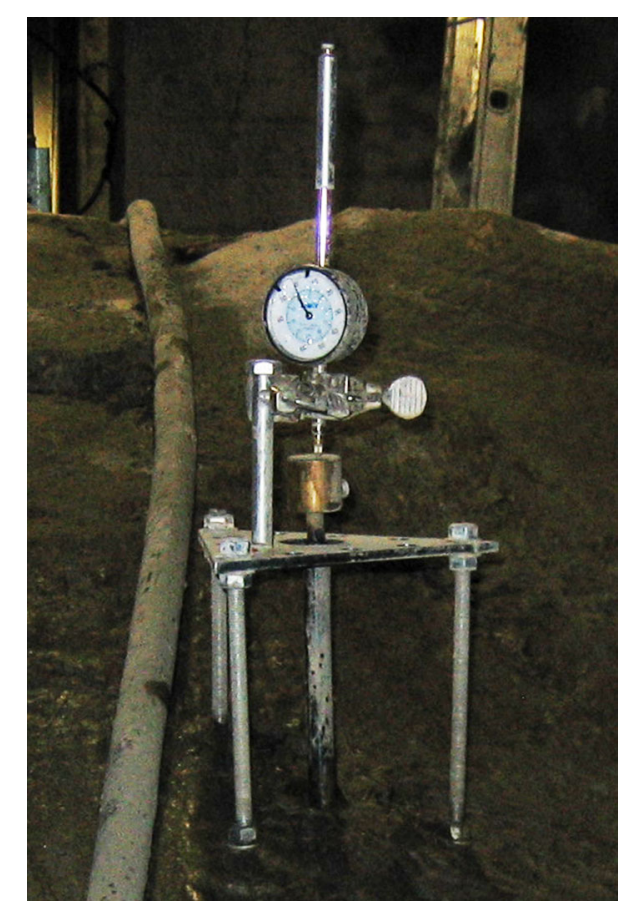

Fig. 10 One of the extensometers used to measure vertical displacement. Image by authors 
recommend that a monitoring system should have two levels of entry, one primary and one secondary, where the latter serves as a backup system to check the performance of the former. Although only one type of measurement equipment was used for each monitored parameter in the studied case, the fact that several devices were installed provided at least some redundancy to the monitoring plan. As a result, a malfunctioning instrument could have been detected more easily.

\subsection{On the Contingency Action Plan}

The last Eurocode requirement states the following (European Committee for Standardization 2004):

- "a plan of contingency actions shall be devised, which may be adopted if the monitoring reveals behaviour outside acceptable limits."

Contingency actions were prepared to manage the three identified risks: exceptionally increased uplift pressure, hydraulic jacking, and washout of infilling material while drilling.

- If $\bar{u}_{\text {joint,lim }}$ were exceeded, equipment was ready to either open up boreholes (that had been temporarily sealed in advance to prevent grout from escaping) or quickly drill additional relief wells.

- If hydraulic jacking occurred owing to an overly large grouting pressure, the grouting pressure was to be reduced immediately until the displacement fell below $\delta_{\text {lim }}$ again. If hydraulic jacking occurred owing to an overly large piezometric water pressure, measures were to be taken to reduce this pressure in the same manner as if $\bar{u}_{\text {piez,lim }}$ was exceeded.

- If a visible amount of infilling material was washed out from any borehole, drilling was to be stopped immediately. To avoid any additional washout, the rock mass around the washout was then to be grouted to stabilize the loose material before drilling continued.

These actions were robust for both the dam stability and the hydraulic jacking case, and they could be put into operation quickly.

\section{The Execution Stage}

Once the monitoring and contingency action plans are prepared, the execution of the project can begin. The Eurocode states the following (European Committee for Standardization 2004):

"During construction, the monitoring shall be carried out as planned."

"The results of the monitoring shall be assessed at appropriate stages and the planned contingency actions shall be put into operation if the limits of behaviour are exceeded."

"Monitoring equipment shall either be replaced or extended if it fails to supply reliable data of appropriate type or in sufficient quantity."

In the following, these requirements are discussed in relation to the actual execution of the project. The procedure outlined in Sects. 4.1-4.4 was generally followed, and the leakage could finally be sealed. The boreholes were injected with a stable grout mix of Cementa Injektering 30 (for which $95 \%$ of the cement particles are smaller than $30 \mu \mathrm{m}$ ) with $2 \%$ addition of SetControl II (a high-performance setting time regulator and dispersion additive based on sulphonated naphthalene polymers and nitrate). Grout properties were tested for the w/c ratio of 0.8 (Table 3). Injected boreholes and amounts of grout injected in each round are presented in detail in Table 4 and Figs. 5 and 7 . In

Table 3 Results of pretesting of grout properties for the w/c ratio of 0.8 at the beginning of the remedial grouting project

\begin{tabular}{lll}
\hline Grout property & Method & Average value \\
\hline Density & Mud balance $^{\mathrm{a}}$ & $1.60 \mathrm{~g} / \mathrm{cm}^{3}$ \\
Marsh funnel time & Marsh funnel $^{\mathrm{b}}$ & $32.8 \mathrm{~s}$ \\
Bleed & Cylinder $^{\mathrm{c}}$ & $1.5 \%$ \\
Penetrability & Filter pump $^{\mathrm{d}}$ & $280 \mathrm{ml}$ \\
\hline
\end{tabular}

a 2 separate batches with 3 measurements from each

b 3 measurements from 1 batch; 1 litre used for each measurement; tested in accordance to Eriksson and Stille (2005)

c 2 separate batches with 3 measurements from each; tested in accordance to SS 137540 (Swedish Standards Institute 2008)

d 2 separate batches with 3 measurements from each; $75 \mu \mathrm{m}$ filter; tested in accordance to SS-EN 14497 (Swedish Standards Institute 2004) 
Table 4 Overview of the executed remedial grouting to seal the local leakage under pier 2 in April and May, 2012

\begin{tabular}{lllr}
\hline Round (date) & Injected boreholes (Figs. 5, 7) & W/c ratio & Grout injected (kg) \\
\hline 1 (2 April) & $53-58$ & 0.55 & 639 \\
2 (11 April) & $31,32,37,38,51,52,53,55,58$ & 0.55 or $0.6^{\mathrm{b}}$ & 209 \\
3 (16 April) & $32,52,53,61,63-68$ & 0.55 & 231 \\
4 (26 April) & $63-65$ & 0.6 or $0.8^{\mathrm{b}}$ & 244 \\
5 (4 May) & 65,69 & 0.8 & 109 \\
6 (9 May) & $5, \mathrm{RW} 12^{\mathrm{a}}, \mathrm{RW} 34^{\mathrm{a}}, \mathrm{G} 2, \mathrm{G} 4$ & 0.8 & 1322 \\
\hline
\end{tabular}

${ }^{a}$ Relief wells

b Different thicknesses used in different boreholes

the first three rounds, $1079 \mathrm{~kg}$ of cement grout was injected in total. Lugeon tests were performed before and in between the rounds to measure the hydraulic conductivity of the rock mass (Table 5). The Lugeon tests performed after two rounds (April 15, 2012) indicated that the fracture had been sealed on both sides of the pier, but that there still was a leakage remaining under it. This was addressed in the subsequent rounds. In the fourth round, a thinner grout was used to penetrate the narrower fractures better than the thicker grout had done in previous rounds. During the fourth round, it was noted that cement grout emerged from relief well RW34. Although the risk of erosion of grout would increase because of the increased gradient, a packer was used to partly seal the relief well to prevent the grout from escaping. In the fifth round, borehole 69 was newly drilled and then grouted along with borehole 65 .

After these five rounds of grouting, a grout curtain enclosing relief well 34 had been created. The watertightness of the grout curtain was tested on May 7, 2012, by sealing the relief well and monitoring the piezometric pressure changes under the monolith (Fig. 11). The piezometric pressure in RW34 increased to $160 \mathrm{kPa}$. Piezometer P3 registered a considerable increase from 30 to $103 \mathrm{kPa}$, whereas piezometer P11 showed a lesser increase from 36 to $49 \mathrm{kPa}$. The other piezometers in the vicinity registered fairly constant or decreasing pressures. Neither extensometer registered any displacement. Although the measurement in P3 locally exceeded $70 \mathrm{kPa}$, no contingency action was put into operation as the average for the monolith remained below the limit of acceptable behaviour, $\bar{u}_{\text {piez,lim }}$.
The piezometric pressure increase in $\mathrm{P} 3$ indicated that the grout curtain leaked there. However, the leakage was judged small, as the surrounding piezometers did not indicate any pressure increase; therefore, the enclosed area around the relief well was grouted next. This was judged the most critical part of the project in terms of risk for hydraulic jacking owing to the required grout pressure of $250 \mathrm{kPa}$ to overcome the high water pressure. However, the new horseshoeshaped grout curtain (Fig. 5) was assumed to serve as a hydraulic barrier, thereby limiting the pressurized area.

During grouting (round 6 in Table 4), the extensometers did not register any movements (in fact, they did not register any movement at all throughout the whole project). Instead, the piezometric pressure in P3 decreased from 62 to $37 \mathrm{kPa}$ and the other adjacent piezometers registered constant, low pressures. Furthermore, as no leakage could be observed visually on the rock surface, the grout curtain was considered completed. A comparison of the situation before and after the grouting shows that the piezometric pressure at $\mathrm{P} 3$ had been reduced significantly from 48 to $27 \mathrm{kPa}$ (Fig. 12).

To summarize the execution of the project, monitoring was performed continuously according to the plan. No contingency action was needed. The preliminary design proved successful and the limits of acceptable behaviour were not exceeded, although locally, at one piezometer, the pressure increased significantly. The monitoring equipment provided reliable data of sufficient quality to base decisions on during the execution of the project, although complementing the extensometers with computer monitoring 
Table 5 Results of performed Lugeon tests in April 2012 before and in between the first three rounds of grouting under pier 2

\begin{tabular}{|c|c|c|c|}
\hline \multirow[t]{2}{*}{ Borehole $^{\mathrm{a}}$} & \multicolumn{3}{|c|}{ Lugeon value (L/min $\mathrm{m} \mathrm{MPa})$} \\
\hline & 1 April & 11 April & 15 April \\
\hline 12 & 48.3 & 54.5 & 19.3 \\
\hline 31 & 64.0 & 72.3 & 0 \\
\hline 32 & 63.6 & 70.9 & 10.4 \\
\hline 34 & 59.4 & 73.7 & - \\
\hline 37 & 38.3 & 9.7 & 0 \\
\hline 38 & 37.9 & 14.5 & 0 \\
\hline 51 & 48.0 & 152.7 & 0 \\
\hline 52 & 47.4 & 53.4 & 16.7 \\
\hline 53 & 48.0 & 51.1 & 34.3 \\
\hline 56 & 38.4 & 0 & 0 \\
\hline 57 & 38.9 & 0 & 0 \\
\hline 58 & 36.9 & 0 & 0 \\
\hline 61 & - & - & 27.8 \\
\hline 63 & - & - & 52.0 \\
\hline 64 & - & - & 50.2 \\
\hline 65 & - & - & 40.2 \\
\hline 66 & - & - & 0.7 \\
\hline 67 & - & - & 29.1 \\
\hline 68 & - & - & 29.2 \\
\hline
\end{tabular}

${ }^{\text {a }}$ Borehole numbers refer to Figs. 5 and 7

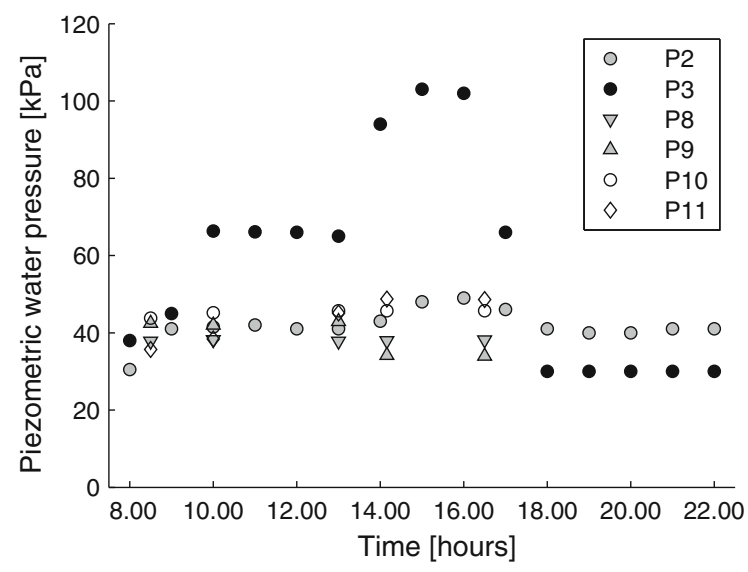

Fig. 11 Registered pressure changes in piezometers under the monolith during the test of the grout curtain on May 7, 2012

of for example grout flows and volumes would have provided even better information about whether and when hydraulic jacking occurred.

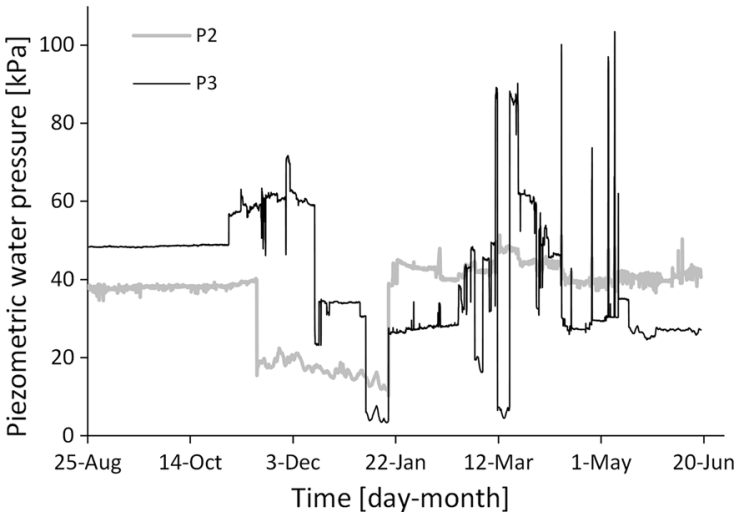

Fig. 12 Registered pressure changes in piezometers P2 and P3 throughout the project. Note the pressure drop in P2 caused by the washout on November 15. The spikes from March to May are caused by grouting activities and tests of the hydraulic conductivity. The last activity took place on May 9

\section{Concluding Remarks on Safety Aspects}

The applied procedure for the remedial grouting of a dam foundation was compared to the risk management framework of the observational method in Eurocode 7. The results showed that the applied procedure mainly agreed with the principles of the observational method. However, some striking inadequacies and interpretation issues were found. They concerned the safety margin that is required to undertake contingency actions successfully and how to assess the probability of exceeding the limit of acceptable behaviour. To address the safety aspects, alternative solutions and interpretations that do not violate Eurocode 7 were suggested and discussed thoroughly.

To summarize the lessons learned, the dam owner must carefully consider the case at hand when designing remedial grouting for dams with very low safety margins. For example, the expected additional loads during grouting may require a corresponding reduction of other driving loads to allow contingency actions to be put into operation without violating dam stability. Toward this end, two options are to lower the reservoir level temporarily and to execute grouting work when the reservoir is ice-free. To avoid inducing a piezometric water pressure increase from the hydraulic jacking of rock joints, the application of new grouting and related measurement techniques can be useful in determining an appropriate grouting pressure. Limiting the pressure improves the sealing 
efficiency and, thereby, the sliding stability of the dam.

Satisfying the observational method in accordance to the suggestions of this paper offers a coherent methodology to manage the safety aspects in the remedial grouting of a concrete dam foundation under which shallow, persistent, horizontal rock joints are present. In conclusion, the authors' recommendations for engineers involved in this type of remedial grouting projects are to consider the observational method as defined in Eurocode 7 and refer to Chapters 4-5 of this paper for suggestions on how the Eurocode requirements can be satisfied. This methodology is in line with the risk-informed dam safety policies and procedures currently being developed worldwide.

Acknowledgments The presented research was funded and supported by the Swedish Hydropower Centre (SVC), the Rock Engineering Research Foundation (BeFo), and the Swedish Research Council Formas. This research was conducted without any involvement of the funding sources. SVC has been established by the Swedish Energy Agency, Elforsk, and Svenska Kraftnät together with the Luleå University of Technology, KTH Royal Institute of Technology, Chalmers University of Technology, and Uppsala University (www.svc. $\mathrm{nu})$.

\section{Compliance with Ethical Standards}

Conflict of interest Fredrik Johansson is part-time employed by the consultant firm that designed the grouting works discussed in this paper.

Open Access This article is distributed under the terms of the Creative Commons Attribution 4.0 International License (http:// creativecommons.org/licenses/by/4.0/), which permits unrestricted use, distribution, and reproduction in any medium, provided you give appropriate credit to the original author(s) and the source, provide a link to the Creative Commons license, and indicate if changes were made.

\section{References}

Australian National Committee on Large Dams (2003) Guidelines on risk assessment. Australian National Committee on Large Dams, Sydney

Baecher GB (2016) Uncertainty in dam safety risk analysis. Georisk 10:92-108. doi:10.1080/17499518.2015.1102 293

Bernstone C, Westberg M, Jeppsson J (2009) Structural assessment of a concrete dam based on uplift pressure monitoring. J Geotech Geoenviron 135:133-142. doi:10. 1061/(ASCE)1090-0241(2009)135:1(133)
Bonin GR, Rombough VT, Carter TG, Jefferies MG (2012) Towards better injection control and verification of rock grouting. Geotech Sp 228:1460-1471. doi:10.1061/ 9780784412350.0122

Brantberger M, Stille H, Eriksson M (2000) Controlling grout spreading in tunnel grouting-analyses and developments of the GIN-method. Tunn Undergr Sp Technol 15:343352. doi:10.1016/S0886-7798(01)00003-7

Bruce D (2007) Managing the design and construction of grouted cut-offs in emergency conditions. Geotech $\mathrm{Sp}$ 168:1-11. doi:10.1061/40912(231)6

Bruce D (2012) Computer monitoring in the grouting industry. Geotech Sp 226:549-564. doi:10.1061/9780784412138. 0021

Bruce D, Gillon M (2003) Seepage evaluation and remediation under existing dams. In: Proceedings of the 21st congress on large dams, Montréal, 16-20 June 2003. International Commission on Large Dams, Paris, Q82

Bruce DA, Naudts A, Smoak WG (1998) High flow reduction in major structures: materials, principles, and case histories. Geotech Sp 80:156-176

Buckby RJ, Key CL, Palmer MJ, Penman JG, Swannell NG (2015) An observational approach to design of a new grout curtain at Wimbleball dam. In: Winter MG, Smith DM, Eldred PJL, Toll DG (eds) Proceedings of the XVI ECSMGE geotechnical engineering for infrastructure and development. ICE Publishing, London, pp 559-654. doi:10.1680/ecsmge.60678

Canadian Dam Association (2007a) Dam safety guidelines. Canadian Dam Association, Toronto

Canadian Dam Association (2007b) Technical bulletin: structural considerations for dam safety. In: Dam safety. Canadian Dam Association, Toronto

Carter TG, Dershowitz W, Shuttle D, Jefferies M (2012) Improved methods of design for grouting fractured rock. Geotech Sp 228:1472-1483. doi:10.1061/9780784412350. 0123

Christiansson R, Olofsson I, Martin D, Holmberg M, Carlsson A (2014) Application of the observational method in the Äspö Expansion project. In: Alejano LR, Perucho A, Olalla C, Jiménez R (eds) Proceedings of international society for rock mechanics regional symposium EUROCK 2014. Taylor \& Francis Group, London, pp 1447-1452

Der Kiureghian A, Ditlevsen O (2009) Aleatory or epistemic? Does it matter? Struct Saf 31:105-112. doi:10.1016/j. strusafe.2008.06.020

Eriksson M, Stille H (2005) Cementinjektering i hårt berg [Cement grouting in hard rock]. Report K22. Swedish Rock Engineering Research, Stockholm

European Committee for Standardization (2004) Eurocode 7: geotechnical design-part 1: general rules. European Committee for Standardization, Brussels

Federal Emergency Management Agency (2015) Federal guidelines for dam safety risk management. Federal Emergency Management Agency, Washington

Federal Energy Regulatory Commission (2002) Engineering guidelines for the evaluation of hydropower projects, chapter III: gravity dams. Federal Energy Regulatory Commission, Washington

Federal Energy Regulatory Commission (2014) Engineering guidelines for risk-informed decision-making-draft. 
Federal Energy Regulatory Commission. http://www.ferc. gov/industries/hydropower/safety/initiatives/risk-

informed-decision-making/eng-guide-ridm.asp. Accessed 28 Jan 2016

Fell R, MacGregor P, Stapledon D, Bell G (2005) Geotechnical engineering of dams. Balkema, Leiden

Fransson ̊, Tsang CF, Rutqvist J, Gustafson G (2010) Estimation of deformation and stiffness of fractures close to tunnels using data from single-hole hydraulic testing and grouting. Int J Rock Mech Min 47:887-893. doi:10.1016/j. ijrmms.2010.05.007

Gothäll R, Stille H (2009) Fracture dilation during grouting. Tunn Undergr Sp Technol 24:126-135. doi:10.1016/j.tust. 2008.05.004

Hanna AW, Plewes HD, Wong R (1993) Investigations of high uplift pressure beneath a concrete dam. Can Geotech J 30:974-990. doi:10.1139/t93-095

Houlsby AC (1990) Construction and design of cement grouting: a guide to grouting in rock foundations. Wiley, New York

International Commission on Large Dams (1993) Bulletin 88: rock foundations for dams. International Commission on Large Dams, Paris

Lin P, Zhu X, Li Q, Liu H, Yu Y (2016) Study on optimal grouting timing for controlling uplift deformation of a super high arch dam. Rock Mech Rock Eng 49:115-142. doi:10.1007/s00603-015-0732-z

Nicholson DP, Tse C, Penny C (1999) The observational method in ground engineering: principles and applications. Construction Industry Research and Information Association, London

Olsson L, Stille H (2002) Alarm thresholds and their use in design of underground openings. In: Pötter R, Klapperich $\mathrm{H}$, Schweiger HF (eds) Probabilistics in geotechnics: technical and economic risk estimation. Verlag Glückauf $\mathrm{GmbH}$, Essen, pp 215-221

Paté-Cornell ME, Benito-Claudio CP (1987) Warning systems: response models and optimization. In: Covello VT, Lave LB, Moghissi A, Uppuluri VRR (eds) Uncertainty in risk assessment, risk management, and decision making. Springer, New York, pp 457-468. doi:10.1007/978-14684-5317-1_36

Peck RB (1969) Advantages and limitations of the observational method in applied soil mechanics. Geotechnique 19:171-187. doi:10.1680/geot.1969.19.2.171

Powderham AJ, Nicholson DP (1996) The way forward. In: Nicholson DP (ed) The observational method in geotechnical engineering. Thomas Telford, London, pp 195-204

Prästings A, Müller R, Larsson S (2014) The observational method applied to a high embankment founded on sulphide clay. Eng Geol 181:112-123. doi:10.1016/j.enggeo.2014. 07.003

Rafi JY (2014) Study of pumping pressure and stop criteria in grouting of rock fractures. Doctoral thesis, TRITA-JOB PHD 1020, KTH Royal Institute of Technology, Stockholm

Rafi JY, Stille H (2014) Control of rock jacking considering spread of grout and grouting pressure. Tunn Undergr Sp Technol 40:1-15. doi:10.1016/j.tust.2013.09.005

Rafi JY, Stille H (2015a) Basic mechanism of elastic jacking and impact of fracture aperture change on grout spread, transmissivity and penetrability. Tunn Undergr Sp Technol 49:174-187. doi:10.1016/j.tust.2015.04.002

Rafi JY, Stille H (2015b) Applicability of using GIN method, by considering theoretical approach of grouting design. Geotech Geol Eng 33:1431-1448. doi:10.1007/s10706-0159910-8

Ruggeri G (2004) Uplift pressures under concrete dams: final report. Working Group on Uplift Pressures under Concrete Dams, ICOLD European Club. http://cnpgb.apambiente. pt/IcoldClub/index.htm. Accessed 20 May 2015

Schubert W (2008) The development of the observational method. Geomech Tunn 1:352-357. doi:10.1002/geot. 200800035

Serra JB, Miranda L (2013) Ground uncertainty implications in the application of the observational method to underground works: comparative examples. Geotech Sp 229:254-270. doi:10.1061/9780784412763.021

Spanish National Committee on Large Dams (2012) Risk analysis applied to management of dam safety: technical guide on operation of dams and reservoirs. Spanish National Committee on Large Dams, Madrid

Spross J (2014) A critical review of the observational method. Licentiate thesis, TRITA-JOB LIC 2024, KTH Royal Institute of Technology, Stockholm

Spross J, Larsson S (2014) On the observational method for groundwater control in the Northern Link tunnel project, Stockholm, Sweden. Bull Eng Geol Environ 73:401-408. doi:10.1007/s10064-013-0501-8

Spross J, Johansson F, Larsson S (2014a) On the use of pore pressure measurements in safety reassessments of concrete dams founded on rock. Georisk 8:117-128. doi:10.1080/ 17499518.2013.864172

Spross J, Johansson F, Stille H, Larsson S (2014b) Towards an improved observational method. In: Alejano LR, Perucho A, Olalla C, Jiménez R (eds) Proceedings of international society for rock mechanics regional symposium EUROCK 2014. Taylor \& Francis Group, London, pp 1435-1440

Statens Vattenfallsverk (1968) Anvisningar för utförande av cementinjektering i berg [Instructions for cement grouting in rock]. Statens Vattenfallsverk, Stockholm

Stille H (2015) Rock grouting - theories and applications. BeFo Rock Engineering Research Foundation, Stockholm

Stille H, Holmberg M (2008) Observational method in rock engineering. In: Mahdi A, Ghazvinian A (eds) Proceedings of the 5th Asian Rock Mechanics Symposium. International Society for Rock Mechanics, Lisbon, pp 157-166

Stille H, Holmberg M (2010) Examples of applications of observational method in tunnelling. Geomech Tunn 3:77-82. doi:10.1002/geot.201000006

Stille H, Gustafson G, Hassler L (2012) Application of new theories and technology for grouting of dams and foundations on rock. Geotech Geol Eng 30:603-624. doi:10.1007/ s10706-012-9512-7

Swedenergy (2012) Kraftföretagens riktlinjer för dammsäkerhet [Swedish hydropower companies' guidelines for dam safety]. Swedenergy, Stockholm

Swedish Standards Institute (2004) Products and systems for the protection and repair of concrete structures-test methods-determination of the filtration stability. SS-EN 14497. Swedish Standards Institute, Stockholm 
Swedish Standards Institute (2008) Concrete testing-cement mortar-bleeding and volume change. SS 137540. Swedish Standards Institute, Stockholm

US Army Corps of Engineers (1984) Grouting technology. EM 1110-2-3506. US Army Corps of Engineers, Washington

US Army Corps of Engineers (2014) Engineering and design: safety of dams - policy and procedures. ER 1110-2-1156. US Army Corps of Engineers, Washington

Weaver KD, Bruce DA (2007) Dam foundation grouting. American Society of Civil Engineers, Reston

Wilson DB (2012) Practice, perspectives, \& trends in U.S. rock grouting. Geotech Sp 228:25-73. doi:10.1061/97807844 12350.0002
Wu TH (2011) 2008 Peck lecture: the observational method, case history and models. J Geotech Geoenviron Eng 137: 862-873. doi:10.1061/(ASCE)GT.1943-5606.0000509

Zetterlund M, Norberg T, Ericsson LO, Rosén L (2011) Framework for value of information analysis in rock mass characterization for grouting purposes. J Constr Eng Manag ASCE 137:486-497. doi:10.1061/(ASCE)CO.1943-7862. 0000265 